\title{
Hereditary model of loose mined rock layer deformation in disintegrators
}

\author{
Volodymyr Nadutyi ${ }^{1 *}$, Oleksandr Tytov ${ }^{1}$, and Ivan Cheberiachko ${ }^{2}$ \\ ${ }^{1}$ National Mining University, Department of Mining Machines and Engineering, 19 Yavornytskoho \\ Ave., 49005 Dnipro, Ukraine \\ ${ }^{2}$ National Mining University, Department of Mining Mechanics, 19 Yavornytskoho Ave., 49005 \\ Dnipro, Ukraine
}

\begin{abstract}
The objective of this work is to substantiate the hereditary character of the stresses and deformations accumulation in loose mined rock during the disintegrators working surfaces convergence. It is shown, in particular, that the layer porosity after compression and the side thrust coefficient depend not only on the applied pressure, but also on the initial porosity. It is substantiated the mechanism of interrelation between the stresses and deformations of a layer. The experimental researches on finegrained granite compression in a rigid matrix have been fulfilled. The approximation of obtained results by polynomial functions has been carried out. The coefficients have been determined by the least-square method. The close agreement of the analytical and the experimental values has been recorded. The initial porosity parameter was put into the equation of dependences of the current porosity and the side thrust coefficient on pressure. The mechanism of the forces distribution on separate particles contacts has been explained in terms of the material compacting hystory. The practical value of the research is in calculating the disintegrators operating parts parameters with account of the mined rock layer condition prior to the act of crushing.
\end{abstract}

\section{Introduction}

It is possible to enhance the efficiency and to reduce the energy consumption of coal, limestone, iron ore, granite and other mining rocks disintegration by correct choice of the disintegrators operating parts parameters. This requires clear understanding of the disintegration process and interrelations of the mined rock condition with the loading parameters.

Today, the questions of a separate rock piece deformation, clamped by two crushing plates, have been explicitly studied. With that, the stressed condition of the rigid body with a given shape was studied [1]. The calculation of this task does not cause problems for modern computer programs $[2,3]$.

But, there is a sufficient number of disintegrator designs, which use the principle of simultaneous crushing of several material layers, when a separate rock piece interacts

\footnotetext{
* Corresponding author: nadutyvp@yandex.ua
} 
mostly with other similar pieces [4]. This method leads to selective mined rock crushing, better disclosure of minerals and less energy consumption.

The number of works devoted to the "in the layer" crushing is small. They are characterized by taking into account the internal friction of loose material, manifested in arising the side thrust coefficient. The side thrust coefficient is expressed in accordance with Mohr-Coulomb model by known formula [5]:

$$
\xi=\frac{\sigma_{3}}{\sigma_{1}}=f(c, \beta)
$$

where $\sigma_{1}, \sigma_{3}$ are the primary stresses; $c$ is the cohesion coefficient; $\beta$ is the internal friction coefficient.

The deformation zone of material between two parallel plates is studied in the contextually similar work [6], with an assumption on constant value of the side thrust coefficient within the whole zone area. But, the obtained theoretical formulas of stresses distribution on crushing plates have satisfactory accuracy only under conditions of low pressures. Their errors increase together with the pressure growth.

In the article [7] based on the analysis of different structure mining rocks reaction on volumetric strain, it is shown, that the stresses distribution tends to hydrostatic one, and the side thrust coefficient tends to unity if the pressure rises unlimitedly.

One can draw the same conclusions by the analysis of very widespread empirical HoekBrown failure criterion of mining rocks [8]:

$$
\sigma_{1}=\sigma_{3}+R_{c} \cdot\left(m_{b} \cdot \frac{\sigma_{3}}{R_{c}}+s\right)^{a},
$$

where $R_{c}$ is the tensile strength in uniaxial compression; $m_{b}, s$ and $a$ are the empirical coefficients, which consider the structural peculiarities of rock massif together with Mohr's enveloping curve.

Also, it is concluded in the work [8], that this Hoek-Brown failure criterion is applicable in conditions, when the rock massif is mainly in cohesive condition. Therefore, GSI (Geological Strength Index), which influences $m_{b}$ and $a$ coefficients values, must be not less than 20 .

On the one hand, Hoek-Brown failure criterion could be used to describe the behavior of piece material state under high pressure, because the value GSI $=20$ corresponds to the disintegrated rock massif consisted of separate rock pieces.

But, on the other hand, there will be some difficulties:

- the porosity of loose material is sufficiently changed during its compression, and this, in turn, influences on its deformation characteristics;

- the porosity of material may be simply determined, but it is difficult to correlate this value with GSI parameter;

- there is a problem to record the "destruction" point of a sample having zero cohesion coefficient, and therefore the destruction of which is not connected with pieces' disintegration; [9];

- the increase in velocity of loading is also of great importance during disintegration

- the availability of moisture has great impact on the friction forces of material particles, especially in case of high porosity $[10,11]$.

According to N. Gersevanov "hydraulic capacity" principle [5], the current porosity of loose material layer is unambiguously determined by the sum of primary stresses on three coordinates and, thus, it does not depend on the loading history. This principle is valid only 
for pressure range up to $0.1-1.0 \mathrm{MPa}$, which are not sufficient for rock massif disintegration.

It has been shown in work [12], that for the case of flat zone of deformation and pressure range up to $4 \mathrm{MPa}$ the initial porosity factor influences the current porosity value not less than the applied pressure.

Real disintegrator constructions are designed to provide average pressures along working surfaces up to several MPa, and locally up to several tens or even hundreds MPa.

Hence, it is necessary to set the influence of applied pressure (in a wide range) and of initial porosity on the current porosity and the side thrust coefficient of mined rock layer in order to describe the disintegrators working process. This is an actual scientific problem.

\section{Analytical substantiation of the hereditary deformation model of mined rock layer}

Every act of mined rock disintegration is followed by different modes of particles interaction. Firstly, mutual slippage of particles occurs, being typical for compacting of very loose material. As the process progresses, sharp edges begin to be cut. Then, the body of particles is destructed with the outflow of splinters into existing pores. At the next stage of compression, the destruction stops and changes to elastic deformation. As a rule, disintegrators are designed to reach the stage of particles bodies destruction [13].

The centers of particle masses do not move with essential absolute displacement values during the destruction act, and the average number of contacts of each particle with neighboring particles rises constantly with reduce in the layer porosity.

Suppose that the average coordination number for the layer is determined as follows:

$$
N=k_{1}-k_{2} \cdot e,
$$

where $e$ is the fractional porosity; $k_{1}$ and $k_{2}$ are the empirical coefficients.

We will take into account the degree of forces development at particles contacts connected with the porosity reduction as the hereditary accumulation of stresses.

Let us consider the process of quasistatic deformation of an elementary volume of material. Suppose, that, initially, the fractional porosity of layer was equal to $e_{0}$ and had an identical value within the whole layer. According to (3), every particle had in average definite number of contacts $N_{0}$.

We assume, that gradient of force increment for the contacts existed at initial time moment, is expressed by dependence:

$$
\frac{d P_{0}}{d x}=s_{0}+s_{1} \cdot\left(x-x_{0}\right)+s_{2} \cdot\left(x-x_{0}\right)^{2}+\ldots+s_{n} \cdot\left(x-x_{0}\right)^{n},
$$

where $x$ is the current contact deformation coordinate; $x_{0}$ is the coordinate of the beginning of the contact deformation; $n$ is the maximum approximation exponent.

As further convergence of particle mass centers proceeds, which is corresponding to initial contact deformation $x_{1}$, an additional number of contacts with corresponding increment of coordination number $\Delta N_{1}$ is formed. Then, we will have $\Delta N_{2}$ increment for $x_{2}$ deformation, and so on. The gradient of force increment, corresponding to $\gamma-$ sequential queue of contacts, will be as follows (scheme in Fig. 1):

$$
\frac{d P_{\gamma}}{d x}=s_{0}+s_{1} \cdot\left(x-x_{\gamma}\right)+s_{2} \cdot\left(x-x_{\gamma}\right)^{2}+\ldots+s_{n} \cdot\left(x-x_{\gamma}\right)^{n} .
$$




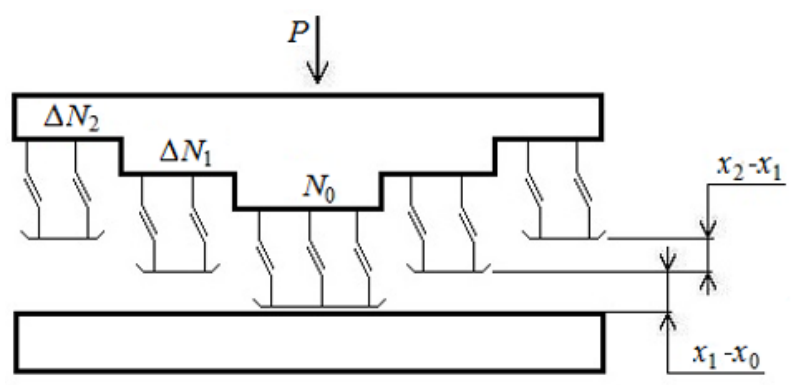

Fig. 1. The scheme of contacts development in loose material during compacting.

The total gradient of force increment on the particle contacts is determined by expression:

$$
\frac{d P}{d x}=N_{0} \cdot \frac{d P_{0}}{d x}+\Delta N_{1} \cdot \frac{d P_{1}}{d x}+\Delta N_{2} \cdot \frac{d P_{2}}{d x}+\ldots+\Delta N_{\gamma} \cdot \frac{d P_{\gamma}}{d x}+\ldots
$$

It is very difficult to calculate the real number of contacts in a layer of material and to determine the contact forces. Hence, we move on from $x$ and $P$ values to $e$ value and force parameter $\lambda$, using expressions

$$
\begin{aligned}
& d e=-w \cdot d x \\
& d \lambda=q \cdot d P,
\end{aligned}
$$

where $w$ and $q$ are some constants.

By analogy to equations (5) and (6), the gradient of increment of the maximum primary compressive stress in a layer will be written as follows:

$$
\begin{aligned}
\frac{d \lambda}{d e}= & -\left(k_{1}-k_{2} \cdot e_{0}\right) \cdot\left[a_{0}+a_{1} \cdot\left(e_{0}-e\right)+a_{2} \cdot\left(e_{0}-e\right)^{2}+\ldots+a_{n} \cdot\left(e_{0}-e\right)^{n}\right]+ \\
& -k_{2} \cdot\left[a_{0} \cdot\left(e_{0}-e\right)+a_{1} \cdot \frac{\left(e_{0}-e\right)^{2}}{2}+a_{2} \cdot \frac{\left(e_{0}-e\right)^{3}}{3}+\ldots+a_{n} \cdot \frac{\left(e_{0}-e\right)^{n+1}}{n+1}\right]
\end{aligned}
$$

The solutions of the last equation are the following hereditary functions:

$$
\begin{aligned}
& \lambda=f\left(e, e_{0}\right) ; \\
& e=\varphi\left(\lambda, e_{0}\right) .
\end{aligned}
$$

Thus, the interrelation between the fractional porosity coefficient and the force parameter has been set analytically, taking into consideration the initial condition of loose mined rock layer.

\section{Experimental research technique}

The fine-grained granite of size less than $0.5 \mathrm{~mm}$ has been put to the research by uniaxial compression in a rigid cylindrical matrix. Slow increase in pressure, in steps, was made for various mass of material, to a value of approximately $40 \mathrm{MPa}$. The normal pressure values on a punch and the values of punch settlement were measured. The results were easily converted to the current fractional porosity dependences on the pressure, which are presented in Fig. 2. 


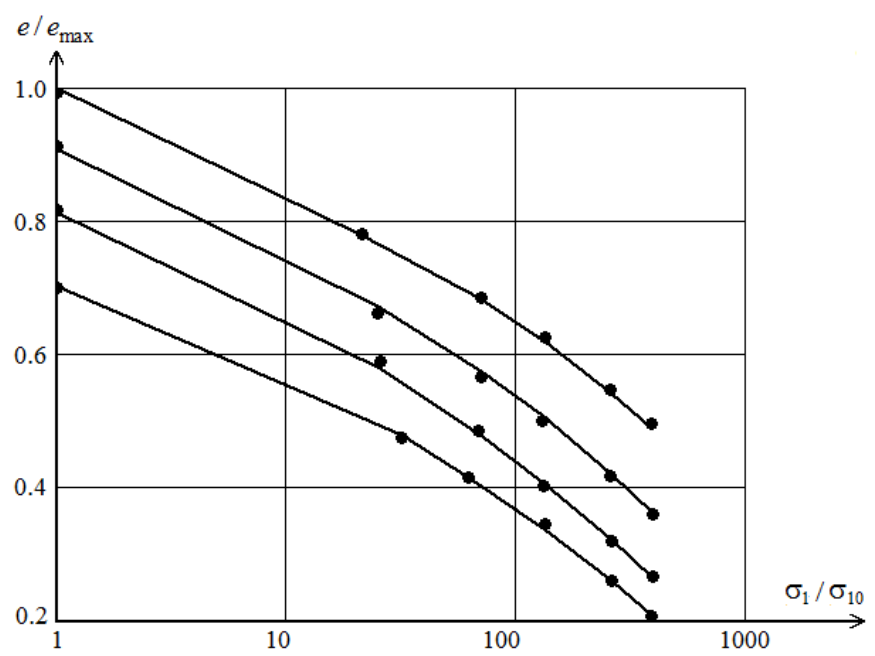

Fig. 2. Odometric dependences for fine-grained granite: lines - theoretical dependences; points experimental values.

The diagrams show almost linear dependence of the fractional porosity on the axial pressure logarithm. Besides, it can be seen the essential influence of the initial fractional porosity on its current value, because the curves shifting value is almost constant within the whole pressure range.

Initially, the matrix was filled with material without preliminary compaction. Different initial values of the fractional porosity may be explained by influence of friction on the side surfaces of the matrix, because the material layer height was in the range from 0.5 to 4.1 diameters. The friction factor would be expected to influence on the side surfaces of the matrix and also on the stresses distribution in the layer at higher pressures. Fig. 3.

The linear model of loose material layer deformation in a rigid matrix is shown in

The balance equation of material elementary layer, having $z$ coordinate value, is as follows:

$$
d \sigma_{1} \cdot \frac{\pi D^{2}}{4}=-f \cdot \xi \cdot \pi D \cdot d z
$$

where $f$ is the coefficient of material friction on the side surfaces of a matrix.

Taking into consideration the above reasons, the side thrust coefficient is supposed to be determined by equation:

$$
\begin{gathered}
\xi=1-\left(1-\xi_{0}\right) \cdot \exp \left(b_{1} \cdot \lambda+b_{2} \cdot \lambda^{2}+\ldots+b_{m} \cdot \lambda^{m}\right) ; \\
\lambda=\ln \left(\frac{\sigma_{1}}{\sigma_{10}}\right),
\end{gathered}
$$

where $\sigma_{10}$ is the basic value, $m$ is the maximum approximation exponent.

If $\sigma_{1} \geq \sigma_{10}$ and all polynomial coefficients are negative, we will obtain $\xi=\xi_{0}$ in case $\sigma_{1}=\sigma_{10}$, and also $\xi \rightarrow 1$ in case $\sigma_{1} \rightarrow \infty$, corresponding to the hydrostatic pressure distribution. 


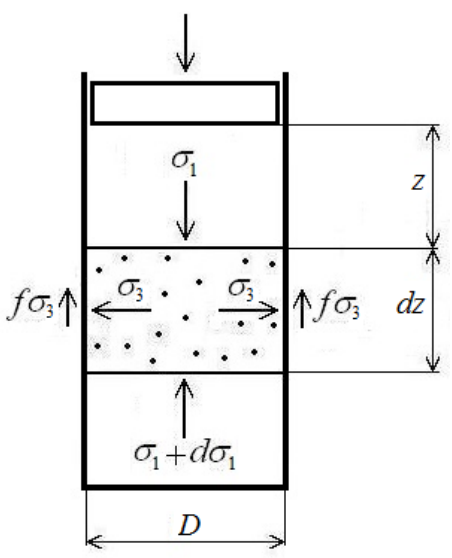

Fig. 3. The linear model of the layer deformation in a rigid matrix.

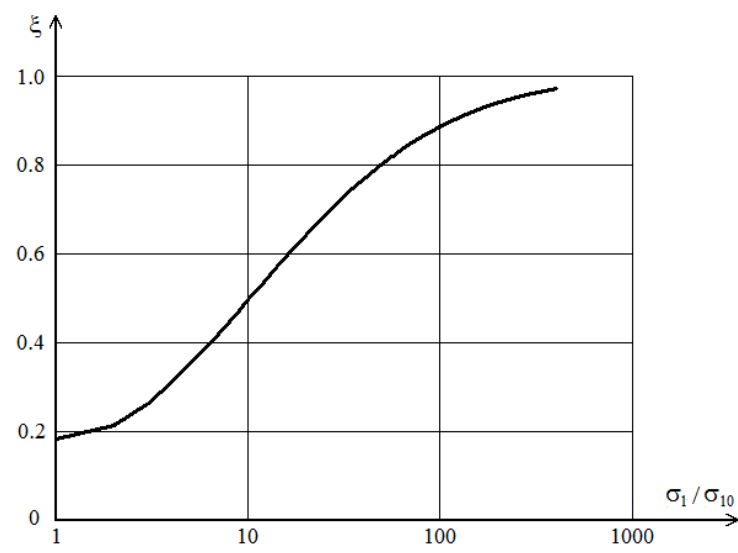

Fig. 4. Dependence of the side thrust coefficient on the maximum primary stress level.

Expression (11) is presented according to Pascal triangle of $u$ exponent as follows:

$$
e=\sum_{i=0}^{u} \sum_{j=0}^{u-i} c_{i, j} \cdot e_{0}^{i} \cdot \lambda^{j} .
$$

The processing of the experimental research data was reduced to the solution of equation (12) with the determination of the coefficients of $b$ and $c$ families by the leastsquare method. Therein, the values of $k_{1}, k_{2}$ and $f$ are given as known values, and also

$$
S=\sum_{v}\left(\frac{e_{v t}-e_{v e}}{e_{v e}}\right)^{2} \rightarrow \min ,
$$

where $e_{v t}$ is the average value within the layer according to (15), $e_{v e}$ is the similar experimental value.

The values calculated by formula (15) are plotted in Fig. 2 (see above) in the form of points.

\section{Results and discussion}

It can be noticed the close agreement of the analytical and experimental values of the fractional porosity in previous research (Fig. 2, see above). This proves the adequacy of the hereditary model of loose material layer deformation.

The analysis of expression (13) character, which is a part of the described model and demonstrates the ratio of the reactive side pressure and the active vertical pressure on the deformed loose layer, is of particular interest.

The results in Fig. 4 show the rise of the side thrust coefficient in case of the pressure increase, and its asymptotic approximating to unity, that corresponds to the given above other authors' data.

In such a way, the behavior of loose material deviates progressively from MohrCoulomb model and approximates to a hydrostatic model with an increase in active pressure. 


\section{Conclusions}

The impossibility to use existing dependences of the side thrust coefficient of loose material for the description of destruction of several layers of particles in disintegrators has been substantiated.

The hereditary model has been developed for accumulating stresses and deformations, during compression of a loose mined rock layer, with account of the initial porosity of a layer.

Experimental research on compression in a rigid matrix of fine-grained granite has been carried out, which confirmed the adequacy of the developed model.

The dependences of the side thrust coefficient on the maximum primary stress and the initial porosity have been determined, based on a linear model of the material deformation in the matrix. They confirm, that the distribution of stresses in the material is close to hydrostatic one at high compression pressure values.

The obtained results allow to specify sufficiently the existing techniques for calculating the disintegrators operating parts parameters as regards 'in the layer' disintegration, in order to enhance their efficiency and to reduce energy consumption.

The authors express their gratitude to professor, Head of Higher Mathematics Department of National Mining University, Olena Sdvyzhkova for the help and consultations during the work performance.

\section{References}

1. Andreev, S.E. (1980). Droblenie, izmelchenie i grokhochenie poleznykh iskopaemykh. Moskva: Nedra.

2. Kolosov, D., Dolgov, O., \& Kolosov, A. (2013). The stress-strain state of the belt on a drum under compression by flat plates. Annual Scientific-Technical Collection - Mining of Mineral Deposits, 351-357. https://doi.org/10.1201/b16354-65

3. Belmas, I.V., Kolosov, D.L., Kolosov, A.L., \& Onyshchenko, S.V. (2018). Stress-strain state of rubber-cable tractive element of tubular shape. Naukovyi Visnyk Natsionalnoho Hirnychoho Universytetu, (2), 60-69.

4. Revnivtsev, V.I., Denisov, G.A., Za1rogatskii, L.P., \& Turkin, V.Y. (1992). Vibratsionnaya desintegratsiya tverdykh materialov. Moskva: Nedra.

5. Dalmatov, B.I. (1988). Mekhanika gruntov, osnovaniya i fundamenty (vkliuchaya spetsialnyy kurs inzhenernoy geologii). Leningrad: Stroyizdat.

6. Nadutyy, V.P., \& Titov, A.A. (2016). Analiz napriazhennogo sostoyaniya ploskoy zony deformirovaniya vibratsionnykh desintegratorov $\mathrm{s}$ uchetom vybrosa materiala. Vibratsii $v$ tekhnitsi ta tekhnolohiiakh, 3(83), 54-58.

7. Babets, D.V., Sdvyzhkova, O.O., Larionov, M.H., \& Tereshchuk, R.M. (2017). Estimation of rock mass stability based on probability approach and rating systems. Naukovyi Visnyk Natsionalnoho Hirnychoho Universytetu, (2), 58-64.

8. Sdvyzhkova, O.O., Babets, D.V., Kravchenko, K.V., \& Smirnov, A.V. (2016). Determining the displacements of rock mass nearby the dismantling chamber under effect of plow longwall. Naukovyi Visnyk Natsionalnoho Hirnychoho Universytetu, (2), 34-42.

9. Sdvyzhkova, O., \& Patynska, R. (2016). Effect of increasing mining on longwall coal mining Western Donbass case study. Studia geotechnika et mechanika, 38(1), 91-99. https://doi.org/10.1515/sgem-2016-0010

10. Bondarenko, A.A. (2012). Mathematical modelling of soil dredger absorption process in the underwater bottomwhole. Metallurgical and Mining Industry, (3), 79-81. orcid.org/0000-0002$\underline{7666-6752}$ 
11. Bondarenko, A.A. (2012). Laws of determination of fine materials suction limits in submarine suction dredge face. Naukovyi Visnyk Natsionalnoho Hirnychoho Universytetu, (4), 59-64. orcid.org/0000-0002-7666-6752

12. Nadutyy, V.P., \& Titov, A.A. (2017). Analiz vliyaniya uplotniayemosti sypuchey gornoy massy na protsess eye deformirovaniya mezhdu ploskimi poverkhnostiami dezintegratorov. Vibratsii $v$ tekhnitsi ta tekhnolohiiakh, 1(84), 35-40.

13. Revnivtsev, V.I., Barzukov, O.P., Ivanov, N.A. and others (1984). Osnovnye zakonomernosti izmeneniya sostoyaniya sloya sypuchego materiala pri szhatii. Obogashchenie poleznykh iskopaemykh, (4), 3-6. 